\title{
Newfoundland and Labrador doctors seek double-digit pay hikes
}

Published at www.cmaj.ca on Apr. 9

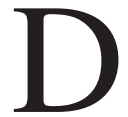
emanding as much as $34 \%$ in pay increases at a time when the recession has forced residents of Newfoundland and Labrador to tighten their belts is "through the roof," says Premier Danny Williams.

But the Newfoundland and Labrador Medical Association argues that such double-digit pay hikes are needed for the province's 1000 physicians to reach "parity" with their Atlantic Canadian counterparts.

Association president Dr. Brendan Lewis says doctors in the province make, on average, about 87 cents for every dollar earned by physicians in other Atlantic provinces. Lewis says salaried family doctors would need an immediate $13 \%$ bump to hit parity, while salaried specialists would require a $27 \%$ hike and emergency room physicians a $34 \%$ hike, to reach the "middle of the pack" in Atlantic Canada.

The association declined to provide its figures comparing doctor compensation in Atlantic Canada, saying the calculations are complicated and not easily boiled down for public consumption.

But Canadian Institute for Health Information (CIHI) numbers suggest that the picture is not quite as gloomy for Newfoundland doctors as implied. CIHI data on the average gross fee-forservice payment per physician who received at least $\$ 60000$ indicate that Newfoundland family doctors typically received \$214 917 in 2007-08, as compared to a national average of $\$ 225521$. Specialists received $\$ 359$ 981, compared to a national average of \$311 171 .

Those numbers, however, do not include salaries or such forms of reimbursement as capitation and only reflect fee-for-service payments above $\$ 60000$, so they do not accurately reflect earnings by doctors reimbursed through a combination of fee-for-service

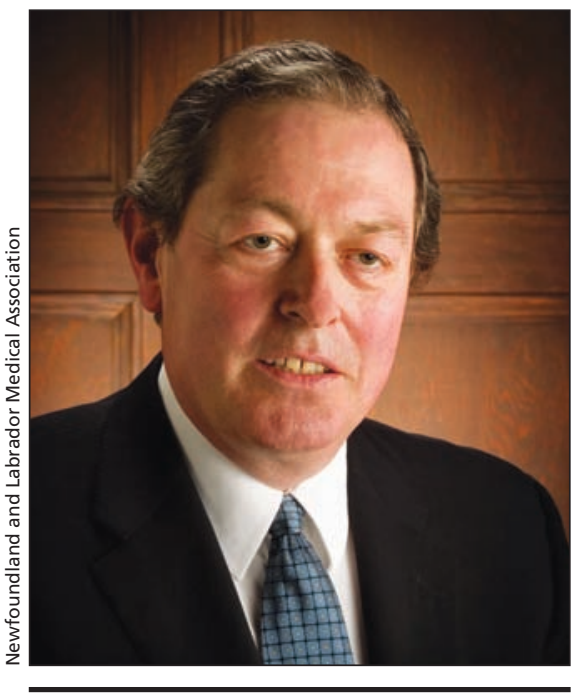

Newfoundland and Labrador Medical Association President Dr. Brendan Lewis says salary demands made by the province's doctors are "all about attracting physicians to our fair province. We want to be competitive."

and salaries (http://secure.cihi.ca/cihi web/en/media_20091126_tab2_e.html).

A separate, unpublished CIHI indice which weights all payments - whether fee-for-service, salary or other form of capitation - for all services, against a national median indicates that Newfoundland and Labrador doctors essentially earn $6.78 \%$ less than a national median of $\$ 224875$ earned by doctors in 2007-08. On that scale, doctors in Alberta ( $7.22 \%$ above the median) were the highest paid in the country, followed by those in British Columbia (5.84\% above), New Brunswick (4.6\% above), Saskatchewan (4.24\% above), Nova Scotia ( $1.68 \%$ above), Ontario (1.68\% below) and Manitoba (4.88\% below). Only doctors in Prince Edward Island (18.28\% below) and Quebec ( $28.66 \%$ below) earned less than those in Newfoundland and Labrador.

Lewis says Newfoundland and Labrador's doctors are seeking the proposed double-digit increases in the first year of a four-year contract, with $3 \%$ increases in each of the final three years. The current labour agreement expired Sept. 30, 2009.

He says the proposals would cost $\$ 80$ million, roughly $25 \%$ more than the $\$ 330$ million that the province now spends on physician compensation.

Lewis adds that the association presented its plan to the government on Mar. 3 but still hasn't received a formal reply.

Williams, though, certainly did respond publicly, telling the media on Mar. 17 that the demands were excessive. "Through the roof. Too high," he told reporters. "Can't be dealt with. Can't be satisfied. Can't be answered."

Lewis says the large increases are needed if the province is to retain enough doctors.

Newfoundland and Labrador is already struggling to recruit and retain physicians, particularly infectious disease specialists, rheumatologists and internists, Lewis says, and without the pay increases, it won't be able to compete with its Atlantic cousins - let alone richer Canadian provinces.

"It's all about attracting physicians to our fair province. We want to be competitive," adds the Corner Brookbased orthopedic surgeon, who predicts that only binding arbitration will resolve the current contract impasse.

Newfoundland and Labrador Finance Minister Tom Marshall, who is responsible for negotiations with the association, was not made available in response to interview requests. Quentin Casey, Halifax, NS

DOI:10.1503/cmaj.109-3231

ONLINE APPENDIX: National weighted benefit rates by specialty stratum and province, 2007-08 (www.cmaj.ca/cgi/content/full/cmaj. 109-3231/DC1). 